\title{
A Facile Electrochemical Analysis to Determine Antioxidant Activity of Bee Pollen
}

\author{
Abdelkrim Rebiai*, Touhami Lanez \\ VTRS Laboratory, University of El Oued, P.O. Box 789, 39000, El-Oued, Algeria \\ *Tel: +213-67688553, *Fax: +213-32238703 \\ *E-mail address: k_rebiai@yahoo.fr
}

\begin{abstract}
The aim of this study was to determine the phenolic and flavonoid content, and antioxidant properties of tow samples of bee pollen harvested from Algeria. The content of total polyphenolic compounds, flavonoids, and antioxidant activity by the cyclic voltammetry method were determined. The contents of polyphenolic compounds was $22.68 \mathrm{mg} / \mathrm{g}$ for the pollen from Blida and 21,9 mg/g for Tipaza pollen. High antioxidant activities were found for the cyclic voltammetry method, with values that ranged from 22,3 to $27,63 \mathrm{mg}$ of $\mathrm{AAE} \cdot \mathrm{g}^{-1}$ pollen. The bee pollen of Blida showed high antioxidant activity probably due to the high content of polyphenolic compounds present in pollen.
\end{abstract}

Keywords: Bee pollen; Antioxidant; Polyphenol; Flavonoids; Voltammetry

\section{INTRODUCTION}

Bee pollen is an agglomerate of pollen grains from various botanical sources, which are collected by the bees and mixed with nectar and secretion from the hypopharyngeal glands such as $\beta$-glycosidase enzymes. Bee pollen has a complex chemical composition constituted of carbohydrates, proteins, aminoacids, vitamins and minerals, and is considered a good nutritional source, beneficial to health [1].

Bee pollen is promoted as a health food with a wide range of nutritional and therapeutic properties [2], triggering beneficial effects to human health and the prevention of prostate problems [3], allergy desensitization [4], arteriosclerosis [5] and tumors [6]. Honeybeecollected pollen is an apicultural product composed of nutritionally valuable substances and containing considerable amounts of polyphenolic compounds, primarily flavonoids, which may act as potent antioxidants [7].

In our continuing search for bee-pollen products [8-10], we have studied the phenolic content, flavonoid content, and antioxidant properties of two samples of bee pollen harvested from (Mai-Jun). 


\section{MATERIAL AND METHODS}

\section{1. Chemicals}

3,4,5-Trihydroxybenzoic acid (gallic acid; GA) (99\%), Ascorbic acid (AA) (99\%), were procured from Alfa Aesar (Etats-Unis). Sodium phosphate $\left(\mathrm{Na}_{3} \mathrm{PO}_{4}\right.$, anhydrous, powder, extra pure), sulfuric acid $\left(\mathrm{H}_{2} \mathrm{SO}_{4}\right)(98 \%)$, aluminium chloride $\left(\mathrm{AlCl}_{3}\right)$ and sodium carbonate $\left(\mathrm{Na}_{2} \mathrm{CO}_{3}\right)$ were purchased from Prolabo (Etats-Unis). The Folin-Ciocalteu reagent (FCR), methanol $(\mathrm{MeOH})$ and hexane were obtained from BIOCHEM chemopharma Co (FRANCE). High purity water, which was used in all experiments. All other reagents used were of analytical grade.

\section{2. Instrumentation and software.}

Spectrophotometric measurements were performed on an UV-1800 Schimadzu Spectrophotometer (double-beam) equipped with $1 \mathrm{~cm}$ quartz cuvettes. PGP301 potentiostat with voltamaster 4 version 7.08 software (radiometer analytical SAS), rotary evaporator (IKA Evaporator RV 06-ML).

\section{3. Bee pollen samples}

Two dehydrated bee pollen samples were collected by beekeepers from two locations in Northwest Algeria (Fig. 1, Table 1), during the period from 2009 to 2010. After collection, the bee pollens were sent to the laboratory and each sample was separately crushed in commercial blender, homogenized and stored in freezer for later analysis.

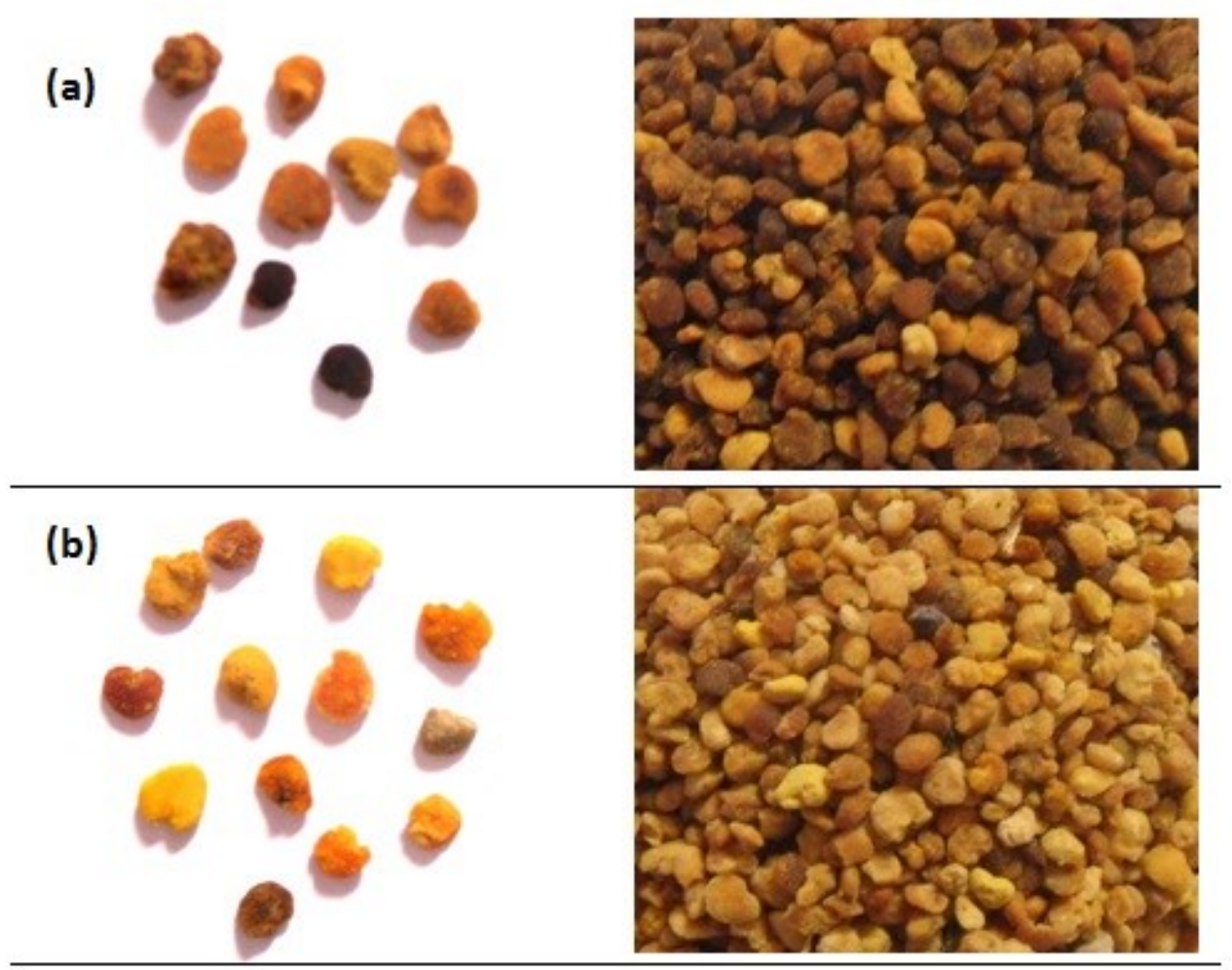

Figure 1. Bee pollen form was pellets that vary in colors: dark yellow, white, brown, orange, and yellow. Then, the microscopic examination of bee pollen pellets was done based on these colors. 
Table 1. Algerian bee pollen samples used in this study on the basis of date of harvest, geographical origin.

\begin{tabular}{|c|c|c|c|c|}
\hline Sample code & $\begin{array}{c}\text { Type of bee } \\
\text { pollen }\end{array}$ & $\begin{array}{c}\text { Date of } \\
\text { harvest }\end{array}$ & $\begin{array}{c}\text { Place of } \\
\text { production }\end{array}$ & Geographical origin \\
\hline P01 & Heteroflora & 2009 & Tipaza & Mountain \\
\hline P02 & Heteroflora & 2010 & $\begin{array}{c}\text { Boufarik, } \\
\text { Blida }\end{array}$ & Field (Mitidja) \\
\hline
\end{tabular}

\section{4. Methods}

\section{4. 1. Extraction of bee pollen compounds}

Extraction of pollen contents was achieved using methanol as a solvent. A $5 \mathrm{~g}$ sample of pollen was extracted by maceration with $50 \mathrm{ml}$ methanol for $72 \mathrm{~h}$ at room temperature. The crude extracts were pooled and concentrated in a rotary evaporator and kept in small $(20 \mathrm{ml})$ sterile dark bottles under refrigerated conditions until use.

\section{4. 2. Determination of Total polyphenolics Content (TPC)}

Total polyphenolic content was determined using Folin- Ciocalteu reagents according to the method of Kumazawa et al [11], briefly described as $0.5 \mathrm{ml}$ of Folin and Ciocalteu's phenol reagent was mixed with $100 \mu \mathrm{l}$ extract solution. After $3 \mathrm{~min}, 2 \mathrm{ml}$ of $20 \%$ aqueous sodium carbonate solution was added to the mixture. The reaction was kept in the dark for 30 min, after which the absorbance was read at $\lambda=760 \mathrm{~nm}$. Gallic acid was used as the standard to produce the calibration curve $(0.03-0.3 \mathrm{mg} / \mathrm{ml})$. The mean of three readings was used and the total polyphenolic content expressed in $\mathrm{mg}$ of gallic acid equivalents (GAEs) (mg/ $100 \mathrm{~g}$ ).

\section{4. 3. Determination of Total Flavonoids Content (TFC).}

For flavonoid contents determination [12], the methanol extracts of pollen was retaken in $1 \mathrm{ml}$ of methanol and treated with $\mathrm{AlCl}_{3}$, methanol solution $(2 \%, 1 \mathrm{ml})$. After $30 \mathrm{~min}$. the solution was mixed well and the intensity of color was measured at $\lambda=430 \mathrm{~nm}$. rutin was used to calculate the standard curve $(0.1$ and $0.02 \mathrm{~g} / \mathrm{L})$ and the results were expressed as $\mathrm{mg}$ of rutin equivalents (REs) per $g$ of extract. All the samples and the standards were analyzed in triplicate.

\section{5. Evaluation of antioxidant capacity by electrochemical techniques}

The measurement of the antioxidant capacity of the studied samples of pollen was performed using an electrochemical method based on cyclic voltammetry techniques [13-15]. Cyclic voltammetry measurements were performed in an electrochemical cell with a volumetric capacity of $50 \mathrm{~mL}$ containing a glassy carbon electrode (GCE) working electrode (radiometer analytical SAS), a $\mathrm{Pt}$ wire counter electrode, and an $\mathrm{Hg} / \mathrm{Hg}_{2} \mathrm{Cl}_{2}$ reference electrode (saturated with $\mathrm{KCl}$ ). The potential was swept in inverse scanning mode starting from -200 to $+800 \mathrm{mV}$ with a scanning rate of $100 \mathrm{mV} / \mathrm{s}$. To avoid reducing the sensitivity of the working electrode, the latter was polished after each cycle by rubbing its surface using alumina oxide (particle size $0.3 \mu \mathrm{m}$ ) before every electrochemical assay. After polishing it 
was rinsed thoroughly with bidistilled water for $30 \mathrm{~s}$. The samples in the electrochemical cell were de-aerated by purging with high purity nitrogen during the electrochemical measurements.

The antioxidant capacity of the studied samples of pollen was obtained using the area below the anodic curve of the voltammogram. The calibration graph is obtained by plotting the area below the anodic curve of the voltammogram of each sample of the standard versus its concentration [16]. Ascorbic acid was used as standard in the calculation of antioxidant capacity of the studied sample of pollen because of their wide spreading in nature.

\section{RESULTS AND DISCUSSION}

\section{1. Determination of Total polyphenolics and Flavonoids}

Table 2 shows the total polyphenol and flavonoid contents of pollen samples. Total polyphenol content in methanolic extract of Tipaza and Blida pollen. as estimated by Folinciocalteu Reagent method shows 22.68 and $21.9 \mathrm{mg}$ gallic acid equivalent per $\mathrm{g}$ of pollen powder respectively. The result indicates that both methanolic extract of Tipaza and Blida pollen contain satisfactory amount of polyphenolic compounds but polyphenolic compounds present in methanolic extract of Tipaza is more.

Table 2. Total polyphenol and total flavonoid $(\mathrm{mg} / \mathrm{g}$ ) contents of methanolic extracts of pollen from Algeria.

\begin{tabular}{|c|c|c|}
\hline Compound (concentration) & P01 & P02 \\
\hline Extraction yield (\%) & 45.45 & 48.09 \\
\hline Total polyphenols (mg/g) & 22.68 & 21.9 \\
\hline Total flavonoids (mg/g) & 11.29 & 14.57 \\
\hline
\end{tabular}

This study showed that total flavonoid contents in the selected pollen as: Blida 14.57 $\mathrm{mg} / \mathrm{g}>$ Tipaza $11.29 \mathrm{mg} / \mathrm{g}$. Variation in the flavonoid content of pollen is mainly attributable to the difference in the preferred regional plants collected by honeybees [17].

\section{2. Evaluation of antioxidant capacity by electrochemical techniques}

The cyclic voltammetry voltammogram obtained for $1 \mathrm{mmol} \cdot \mathrm{l}^{-1}$ of ascorbic in $\mathrm{pH} 7,0.2$ $\mathrm{mol} \cdot \mathrm{l}^{-1}$ phosphate buffer solution and $0.1 \mathrm{~mol} \cdot \mathrm{l}^{-1} \mathrm{KCl}$ as a supporting electrolyte using a 3 mm-diameter glassy carbon electrode present typical irreversible oxidation processes with the existence of an irreversible one oxidation peak at $0.26 \mathrm{~V}$ for ascorbic acid (Fig. 2).

The same irreversible electrochemical behavior was observed for pollen sample extract Fig. 3, although with oxidation potential value of pollen extract is less positive than ascorbic acid, around $0.18 \mathrm{~V}$, however these results do not indicate that, under the electrochemical conditions used, the pollen extract has an antioxidant capacity more than ascorbic. The second oxidation potential value of pollen extract is more positive than ascorbic acid. 


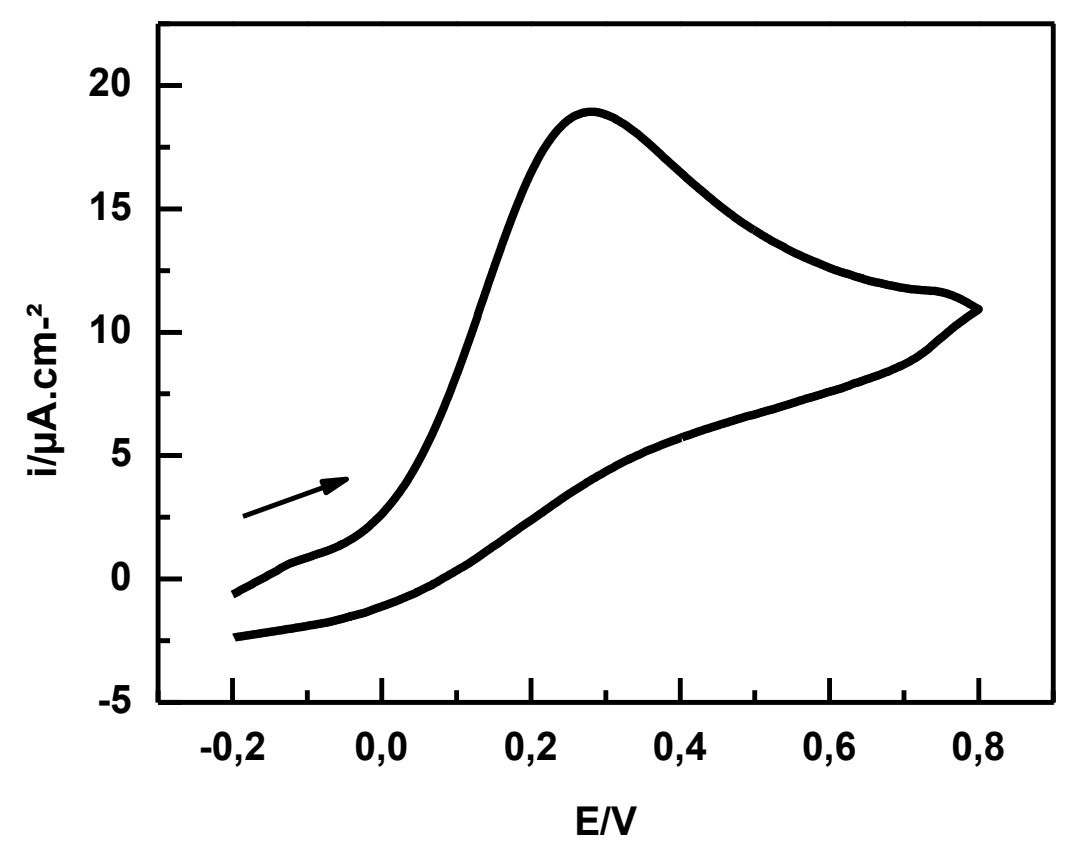

Fig. 2. Cyclic voltammograms obtained in $1 \mathrm{mmol} \cdot \mathrm{l}^{-1}$ of ascorbic in $\mathrm{pH} 7,0.1 \mathrm{~mol} \cdot \mathrm{l}^{-1}$ phosphate buffer solution containing $0.1 \mathrm{~mol} \cdot 1^{-1} \mathrm{KCl}$ at scan rate $100 \mathrm{mV} / \mathrm{s}$.

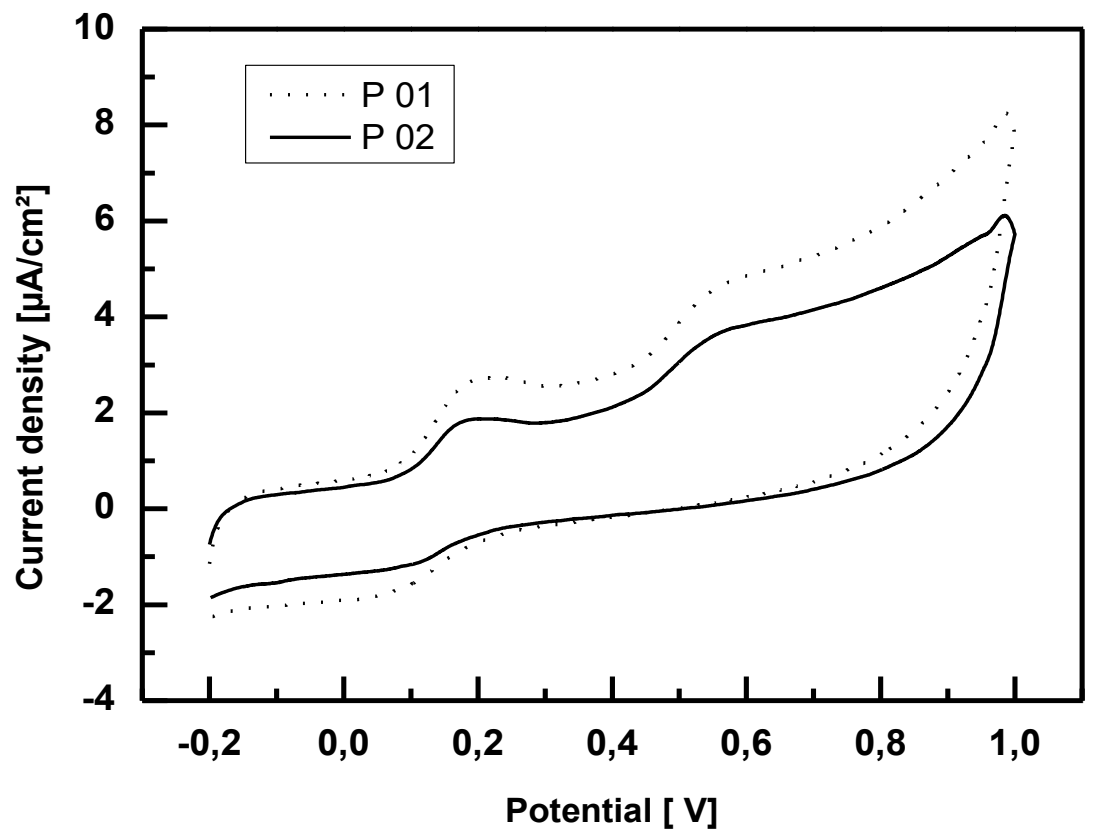

Fig. 3. Cyclic voltammograms of $20 \mathrm{mg} / \mathrm{ml}$ methanolic extracts of pollen in $\mathrm{pH} 7,0.2 \mathrm{~mol} \cdot \mathrm{l}^{-1}$ phosphate buffer solution containing $0.1 \mathrm{~mol} \cdot \cdot^{-1} \mathrm{KCl}$ at scan rate $100 \mathrm{mV} / \mathrm{s}$.

Shows the voltammograms for the pollen extracts. The extracts of pollen, have two peaks. 
The Cyclic voltammograms, at different concentrations of ascorbic and gallic acids, are shown in Fig. 4. As can be seen there is an increase in peak current with the increase in ascorbic or gallic acids concentrations which leads to a linear relation between these two parameters.

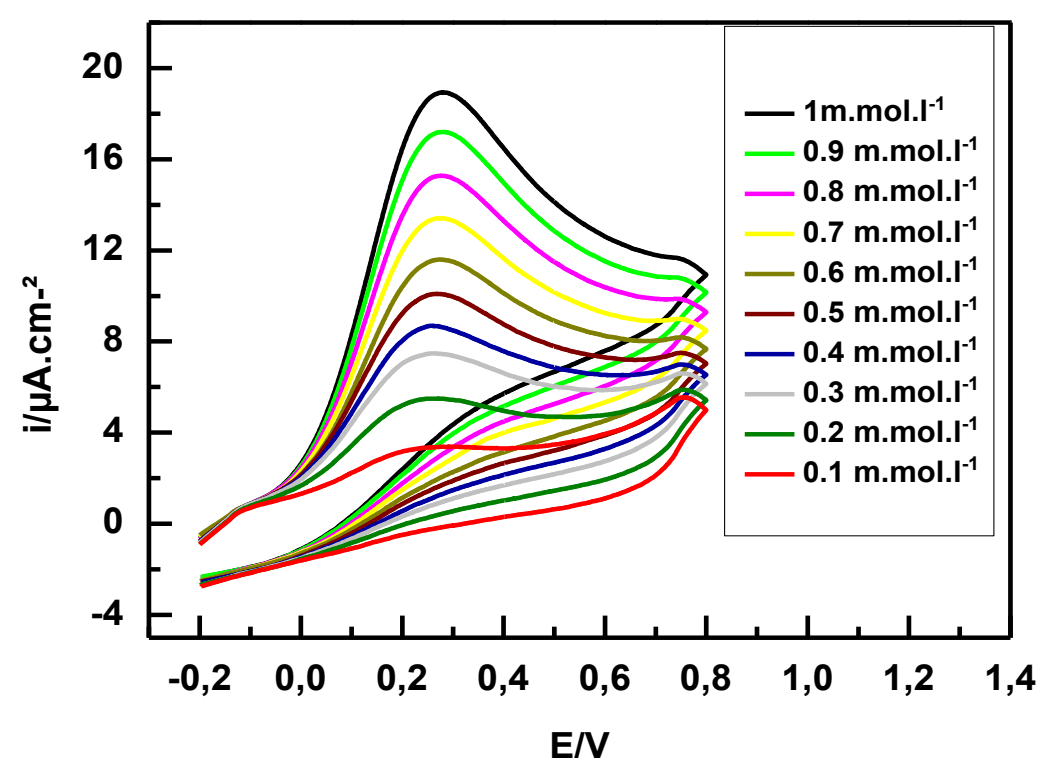

Fig. 4. Cyclic voltammograms referring to different ascorbic acid concentrations.

In order to express the antioxidant capacity of the pollen extract in equivalent terms of ascorbic acid equivalent antioxidant capacity (AEAC), different concentrations of the standard ascorbic were plotted verses the area of the anodic wave (AAW).

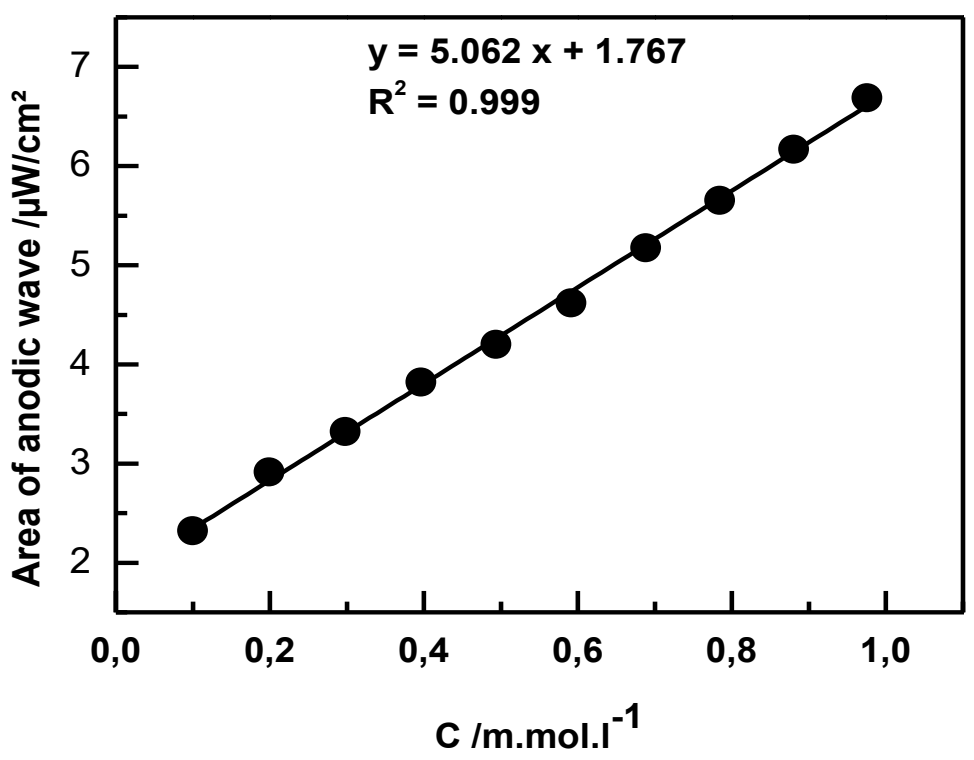

Fig. 5. Calibration curve obtained by cyclic voltammetry method expressed as ascorbic acid equivalent/l. 
The equation obtained from the linear calibration graph in the studied concentration range for ascorbic, $y=5.0628 x+1.7674$, with a correlation coefficient of $\mathrm{R}^{2}=0.999$ for both equations Fig. 5. In Table. 3 the ascorbic acid equivalent antioxidant capacity (AEAC) of the P01 (Tipaza) and P02 (Blida) calculated from the calibration graphs is equal to 22.30 and $27.63 \mathrm{mg} / \mathrm{g}$.

Table. 3. The antioxidant capacity of bee pollen calculated using cyclic voltammetry (CV).

\begin{tabular}{|c|c|}
\hline Sample code & AEAC $(\mathbf{m g} / \mathbf{g})$ \\
\hline P01 & 22.30 \\
\hline P02 & 27.63 \\
\hline
\end{tabular}

The results show that the antioxidant capacity, expressed in terms of ascorbic (AEAC) equivalent antioxidant capacity obtained from electrochemical experiments is higher. This outcome can be attributed to the over estimation of the total polyphenolic content due to the interferences of other non-phenolic species like reduction sugars.

\section{CONCLUSION}

The results of this preliminary study, conducted on bee pollen from two different sources from Algeria, demonstrated that the polyphenolic and flavonoid composition, rather that the concentration, could be the determinant factor. Our results suggested that the antioxidant capacity of samples might be associated with their specific compounds.

The cyclic voltammetry method is recommended as it represents a relatively clean chemical system, easy to control, is not affected by turbid solutions of the extracts and is fairly rapid and cost-effective. In conclusion, future analysis is required, not only in testing other different systems of evaluating the antioxidant activity, but also in separation and identification the specific compounds in bee pollens with different botanical origin, in order to elucidate the differences between various samples.

\section{References}

[1] M. R. G. Campos, S. Bogdanov, L. M. B. de Almeida-Muradian, T. Szczesna, Y. Mancebo, C. Frigerio, F. Ferreira, J. Apicult. Res. 47 (2008) 157.

[2] M. Yamaguchi, R. Hamamoto, S. Uchiyama, K. Ishiyama, K. Hashimoto, J. Health Sci. 52 (2006) 44.

[3] D. A. Shoskes, Urology 60 (2002) 36.

[4] A. Mizrahi, Y. Lensky, Bee Products: Properties, Applications and Apitherapy. Springer-Verlag, New York, NY, USA, 1997, p. 27. 
[5] J. Wojcicki, L. Samochowiec, B. Bartlomowicz, A. Hinek, M. Jaworska, B. Gawronska-Szklarz, Atherosclerosis 62 (1986) 39.

[6] X. Zhang, F. K. Habib, M. Ross, U. Burger, A. Lewenstein, K. Rose, J. Jaton, J. Med. Chem. 38 (1995) 735.

[7] G. Kroyer, N. Hegedus, Innov. Food Sci. Emerg. Technol. 2 (2001) 171.

[8] A. C. S. Lins, T. M. S. Silva, C. A. Câmara, E. M. S. Silva, B. M. Freitas, Rev. Bras. Farmacogn. 13 (2003) 40.

[9] T. M. S. Silva, C. A. Camara, A. C. S. Lins, J. M. Barbosa, E. M. S. Silva, B. M. Freitas, F. A. R. Santos, J. Food Comp. Anal. 19 (2006) 507.

[10] T. M. S. Silva, C. A. Camara, A. C. S. Lins, M. F. Agra, E. M. S. Silva, I. T. Reis, B. M. Freitas, Ann. Acad. Bras. Cienc. 81 (2009)173.

[11] S. Kumazawa, T. Hamaska, T. Nakayama, Food Chem. 84 (2004) 329.

[12] C. Chang, M. H. Yang, H. M. Wen, J. C. Chern, J. Food and Drug Anal. 3 (2002) 178.

[13] A. Rebiai, T. Lanez, M. L. Belfar, Int. J. Phar. 7 (2011) 113.

[14] R. Keyrouz, M. L. Abasq, C. Le Bourvellec, N. Blanc, L. Audibert, E. ArGall, D. Hauchard, Food Chem. 126 (2011) 831.

[15] H. Zieliński, D. Zielińska, H. Kostyra, J. Food Chem. 130 (2012) 1098.

[16] B. S. Chevion, M. A. Roberts, M. Chevion, Free. Rad. Bio. Med. 28 (2000) 860.

[17] M. Leja, A. Mareczek, G. Wyżgolik, J. Klepacz-Baniak, K. Czekońska, Food Chem. 100 (2007) 237-240. 